\title{
Epigenetic Silencing of TET1 Mediated Hydroxymethylation of Base Excision Repair Pathway During Lung Carcinogenesis
}

Hong-qiang Chen

Army Medical University

Dong-jiao Chen

Army Medical University

Yan Li

Army Medical University

Wen-bo Yuan

Army Medical University

Jun Fan

Army Medical University

Zhe Zhang

Army Medical University

Fei Han

Army Medical University

Xiao Jiang

Army Medical University

Jian-ping Chen

Army Medical University

Dan-dan Wang

Army Medical University

Jia Cao

Army Medical University

Jin-yi Liu

Army Medical University

Wen-bin Liu ( $\square$ liuwenbin@tmmu.edu.cn )

Third Military Medical University https://orcid.org/0000-0003-3796-886X

\section{Research}

Keywords: TET1, Base excision repair, Lung cancer, DNA hydroxymethylation, DNA methylation, Chemical carcinogenesis 
Posted Date: June 4th, 2020

DOl: https://doi.org/10.21203/rs.3.rs-32537/v1

License: (c) (i) This work is licensed under a Creative Commons Attribution 4.0 International License. Read Full License

Version of Record: A version of this preprint was published at Environmental Pollution on January 1st, 2021. See the published version at https://doi.org/10.1016/j.envpol.2020.115860. 


\section{Abstract}

Backgroud: The methylcytosine dioxygenase Ten-eleven translocation 1 (TET1) is an important regulator for the balance of DNA methylation and hydroxymethylation through various pathways. Increasing evidence has suggested that TET1 probably involved in DNA methylation and demethylation dysregulation during chemical carcinogenesis. However, the role and mechanism of TET1 during lung cancer remains unclear.

Methods: The gene and protein expression were detected by qRT-PCR, Western blot and immunohistochemistry during lung carcinogenesis. Methylation and hydroxymethylation status were evaluated by MeDIP-qPCR and hMeDIP-qPCR. The effect and mechanism of TET1 on lung cancer were identified both in vitro and in vivo models.

Results: In this study, we found that TET1 expression was significantly down-regulated and the methylation level was significantly up-regulated in 3-MCA-induced cell malignant transformation model, rat chemical carcinogenesis model, and human lung cancer tissues. Demethylation experiment further confirmed that DNA methylation negatively regulated TET1 gene expression. TET1 overexpression inhibited cell proliferation, migration and invasion in vitro and in vivo, while knockdown of TET1 resulted in an opposite phenotype. DNA hydroxymethylation level in the promoter region of base excision repair (BER) pathway key genes XRCC1, OGG1, APEX1 significantly decreased and the degree of methylation gradually increased in malignant transformed cells. After differential expression of TET1, the level of hydroxymethylation, methylation and expression of these genes also changed significantly. Furthermore, TET1 binds to the promoter of XRCC1, OGG1, and APEX1 to maintain them hydroxymethylated. Blockade of BER pathway key gene alone or in combination significantly diminished the effect of TET1.

Conclusions: Our study demonstrated for the first time that TET1 gene expression is regulated by DNA methylation and TET1-mediated hydroxymethylation regulates BER pathway to inhibit the proliferation, migration and invasion during the 3-MCA-induced lung carcinogenesis. These results may suggest that TET1 gene can be used as a potential biomarker and therapy target for lung cancer.

\section{Backgroud}

Lung cancer has been the most common cancer and the leading cause of cancer-related death among all patients worldwide [1]. Epidemiological studies have found that more than $80 \%$ of human lung cancers are closely related to human exposure to chemical carcinogens in living and working environments [2, 3]. In recent years, the important role of epigenetic regulation in chemical carcinogenesis has been gradually discovered and confirmed [4]. As the main regulation mode of epigenetics, DNA methylation is considered to be the "third pathway" leading to inactivation of tumor suppressor genes and tumorigenesis following loss of heterozygosity and gene mutation [5]. Studies have shown that DNA methylation not only helps to elucidate the mechanism of chemical carcinogenesis, but also can be used as an epigenetic biomarker 
for early diagnosis and prevention of cancer, screening of susceptible populations and assessment of carcinogenic risk of environmental exposure [6-8].

DNA methylation is mainly 5-methylcytosine (5-mC), which strictly regulates gene expression in a dynamic equilibrium by DNMT1, DNMT3a, and DNMT3b in higher eukaryotic cells [9]. Recent studies have found Ten-eleven translocation (TET) family can catalyze the conversion of 5-mC to 5hydroxymethylcytosine (5-hmC), then thus regulated the balance of DNA methylation [10]. TET protein family consists of three members, TET1, TET2 and TET3, which belong to ketoglutarate and Fe ${ }^{2+}$ dependent dioxygenase and can produce catalytic oxidation. TET1 and 5-hmC levels are significantly correlated with the occurrence, development and prognosis of human solid tumors [11]. However, the regulatory mechanism of TET1 gene and 5-hmC during lung cancer is still unknown.

TET1 protein could oxidize 5-hydroxymethyl cytosine to 5-carboxyl cytosine, and that glycosidase TDG could specifically recognize and remove 5-carboxyl cytosine from DNA, and then initiate base excision repair (BER) pathway to complete DNA demethylation [10]. OGG1, APEX1 and XRCC1 genes are mainly responsible for the process of removing damaged bases, producing single strand breaks and repairing and closing after base excision $[12,13]$. Reduced expression or functional deficiency of any of these genes may affect the efficiency of repairing DNA damage, lead to damage and increase the susceptibility of tumors. TET1-mediated demethylation requires the involvement of BER pathway in embryonic stem cells [14]. Inhibitor treatment of the key genes APEX1 and PARP1 of the BER pathway, or knockdown of TDG expression can block the demethylation process [15]. However, how TET1 regulates the coordination of BER pathway and participates in demethylation process during lung carcinogenesis remains unclear. In this study, we explored the epigenetic regulation, function and mechanism of TET1 gene and BER pathway during lung carcinogenesis.

\section{Materials And Methods}

\section{Cell culture}

The human bronchial epithelial cell line HBE and lung cancer cell lines A549, SPC-A-1, LTEP-a-2, NCl$\mathrm{H} 520, \mathrm{NCl}-\mathrm{H} 460, \mathrm{NCl}-\mathrm{H} 1975, \mathrm{NCl}-\mathrm{H} 358$ and 95D were purchased from the cell bank of the Type Culture Collection of the Chinese Academy of Sciences (Shanghai, China) and the American Type Culture Collection (ATCC, USA). HBE cells were cultured in DMEM medium (high-glucose) containing $10 \%$ fetal bovine serum (Gibco, USA) at $5 \% \mathrm{CO}_{2}$ and $37^{\circ} \mathrm{C}$, and other cells were cultured in RPMI-1640 medium containing $10 \%$ fetal bovine serum.

\section{Cell malignant transformation model}

The malignant transformation model of HBE cells was established referring to our previous study [16]. Briefly, the HBE cells were divided and assigned to either the 3-MCA-treated (purity $\geq 97.5 \%$, as determined by high-performance liquid chromatography; Sigma, USA) group or the dimethylsulfoxide (DMSO) treated group. According to the literature $[17,18], 1$ and $10 \mu \mathrm{M}$ of 3-MCA were determined to be used for 
the experiment. However, the results of $1 \mu \mathrm{M}$ 3-MCA group were negative. Finally, $10 \mu \mathrm{M}$ of 3-MCA was selected for continuous treatment of HBE cells for 45 generations. Cell samples from the 5th, 15th, 25th, 35th, and 45th passages were collected and named P5, P15, P25, P35, and P45, respectively. The malignancy of 3-MCA treated HBE cells were determined by the CCK-8 assay, soft agar assay and in vivo tumorigenicity assay to ensure successful establishment of the malignant transformation model.

\section{Animal model and tissue samples}

Chemical-induced rat lung cancer model was established as described in our previous study [19]. All procedures were approved by the Animal Care Committee of Third Military Medical University and carried out instrict compliance with the relevant guidelines. Briefly, Wistar rats aged 6 weeks and weighing 180$220 \mathrm{~g}$ used in our experiments were randomly divided into two groups: experimental group and control group. Rats were treated with a single dose of $10 \mathrm{mg} 3-\mathrm{MCA}$ in iodized oil by left intra-bronchial instillation as the experimental group. Control rats were kept with iodized oil in the same conditions. Rats were sacrificed within 75 days after instillation. The left lungs were cut into two pieces, one of which was kept frozen for DNA, mRNA and protein extraction, and the other was fixed in $4 \%$ formaldehyde, embedded in paraffin, and routinely histopathologically evaluated as normal, precancerous, tumor according to diagnostic criteria described previously [19].

\section{Human tissue samples}

The lung tumor tissues and adjacent normal tissues of 75 patients with lung cancer randomly selected from the participants enrolled in our previous study [20]. All participants signed informed consent and all procedures and implements were approved by the Ethics Committee of Third Military Medical University. Briefly, the tumor tissues and adjacent normal tissues were collected from the surgically removed tissues of patients with lung cancer who were operated in the First Affiliated Hospital of the Army Medical University (the Third Military Medical University). All the collected tumor tissues were verified by pathology. The lung tissues $5 \mathrm{~cm}$ away from the edge of tumor resection were taken as the adjacent normal control group. All the collected tissue samples were collected after the patients were informed in advance. The tissue samples were immediately frozen in liquid nitrogen and stored at $-80{ }^{\circ} \mathrm{C}$.

\section{RNA extraction, real-time quantitative reverse-transcription polymerase chain reaction (qRT-PCR) and RT-PCR}

Cells or tissue samples were collected and the total RNA was extracted by using TRIzol reagent. According to the manufacturer's instructions, reverse transcription of RNA (2-4 $\mu \mathrm{g})$ was performed by the GoScript $^{\text {TM }}$ reverse transcription system (Promega, USA). PCR amplification of cDNA templates was performed using a Fluorometric Assay Kit (Promega, USA). Real-time quantitative RT-PCR and RT-PCR analyses were performed as previously described [21]. The primer sequences of qRT-PCR and RT-PCR were shown in Supplementary Table S1 and Table S2. The $2^{-\Delta \Delta C t}$ method was used to analyze the results of qRT-PCR. All analyses were performed at least three times in triplicate.

\section{Protein extraction and Western blot}


A proper amount of cells or tissue samples were added to the RIPA protein lysate for lysis, and the protein was extracted after centrifugation at low temperature. Protein concentration was measured according to the instructions of BCA protein concentration test kit. After the preparation of SDS-PAGE gel, about $80 \mu \mathrm{g}$ for each sample were taken to be electrophoretic and transferred to the PVDF membrane. The PVDF membrane was blocked with $5 \%$ skimmed milk powder and then incubated with primary antibodies at 4 ${ }^{\circ} \mathrm{C}$ overnight. The antibodies used in this study were anti-TET1 (1:1000; Sant Cruz, USA), anti-XRCC1 (1:800; Boster, China), anti-OGG1 (1:1000; Boster, China), anti-APEX1 (1:1000; Boster, China), anti-betaactin (1:1000; Beyotime, China). The membrane was washed with TBST buffer for 3 times, then incubated secondary antibody at room temperature, and finally detected by ECL chemiluminescent substrate (Thermo, USA).

\section{Immunohistochemistry}

Immunohistochemistry was performed on serial sections and used to detect the expression of TET1 protein expression using protocols previously described [19]. Thick sections with $4-\mu m$ thickness were incubated with anti-TET1 antibody. The immunohistochemical analyses were evaluated by two individuals who were blinded to the sample information. Nucleoplasm immunostaining was considered evidence of expression. Expression of the proteins was scored according to the staining intensity $(0$, negative; 1 , weak; 2 , moderate; and 3 , strong) and the proportion of positive cells ( 0 , negative; 1 , positive in $<25 \%$; 2 , positive in $25-49 \%$; 3 , positive in $50-74 \%$; 4 , positive in $\geq 75 \%$ of cells). If the multiplication of the two scores were more than 6 , the expression of TET1 was considered to be high expression.

\section{Demethylation experiment}

The P45 3-MCA treated HBE cells were inoculated into six-well plates at the concentration of $4 \times 10^{5}$ cells per well. Demethylation agent 5-aza-2'-deoxycytidine (5-aza-dC) (Sigma) with the concentration of $10 \mu \mathrm{M}$ was used to continuously treat the cells in the six-well plates for 3 days. The cells were then collected and used to extract the DNA, RNA and protein. MeDIP-qPCR was used to detect the methylation level of TET1. QRT-PCR and Western blot were used to detect the mRNA and protein expression of TET1. The analyses were repeated at least three times.

\section{Cell transfection experiment}

For overexpression, the CDNA of the human TET1 gene was cloned into the mammalian expression vector pCMV6-AC-GFP. For gene knockdown, TET1 shRNAs and a negative control shRNA were designed and synthesized, and then subcloned into shRNA-GFP vector. Cell transfection was performed as previously described [22]. Briefly, cells were seeded in plats and cultured for 24 hours. Then, the mixed system of ViaFect ${ }^{\text {TM }}$ transfection reagent (Promega, USA), the target plasmid, Opti-MEM medium and complete medium were prepared and replaced the medium in the culture dishes. After $48 \mathrm{~h}$ of transfection, the fluorescence of the cells was observed with an inverted fluorescence microscope. Cells were obtained for the extraction of RNA and protein. The stably cells were screened by G418. Stable cells with TET1 overexpression or knockdown were confirmed by RT-PCR and Western blot.

\section{Cell proliferation assay}


Cells were evenly seeded in 96-well plates and transfected after culture for 24 hours. The mixed system of CCK-8 solution and RPMI-1640 complete medium were prepared following the instructions of the CCK-8 kit (Dojindo, Japan). Then, the proliferation of cells was detected respectively, after transfected for $24 \mathrm{~h}$, $48 \mathrm{~h}, 72 \mathrm{~h}$ and $96 \mathrm{~h}$ (named as D1, D2, D3 and D4). Finally, OD value was quantified by measuring the absorbance at $450 \mathrm{~nm}$. All assays were performed at least three times in triplicate.

\section{Clone formation experiment}

Approximately 1000 cells transfected for 48 hours were seeded in six-well plates, and appropriate concentration of G418 was used to treat the cells for 14-21 days. When clones with a stable plasmid integrated into genomic DNA were formatted, $4 \%$ paraformaldehyde was used to fix the cells and crystal violet staining solution (Sigma) was used to stain the clones. Clones contained more than 50 cells were considered to be positive clones. All assays were performed at least three times in triplicate.

\section{Soft agar assay}

Soft agar assay was performed as previously described [22]. Briefly, the lower layer agar and the upper layer agar were prepared in a 24-well plate. Cells were mixed with the upper layer agar, and incubate in a $37^{\circ} \mathrm{C}$ cell incubator for $2-3$ weeks. Clones that contained more than 50 cells were considered as positive clones and counted by phase-contrast microscopy. All assays were performed at least triplicate.

\section{Scratch healing experiment}

Cells were seeded in six-well plates, and transfected after cultured for $24 \mathrm{~h}$. Toothpicks were used to scratch in the six-well plates after transfected for $24 \mathrm{~h}$. After scratching for $0 \mathrm{~h}$ and $48 \mathrm{~h}$, the same point of the scratched cells were took photos to observe the migration. Finally, the distance of cell migration was analyzed statistically. All assays were carried out at least three times in triplicate.

\section{Transwell assay}

Transwell assay was performed as previously described [22]. Briefly, approximately $2 \times 10^{4}$ cells that were transfected for 24 hours were seeded in the Transwell chamber (Corning, USA). Transwell chamber with or without Matrigel gel was used for the detection of cell invasion and cell migration, respectively. After culturing for another $24 \mathrm{~h}$, the cells were fixed by $4 \%$ paraformaldehyde at room temperature and stained by crystal violet staining solution for $30 \mathrm{~min}$. The inverted microscope was used to take photos of the stained cells. Finally, five different fields were randomly selected for analysis. All assays were performed at least three times in triplicate.

\section{Nude mouse tumorigenesis experiment}

All experimental procedures were approved by the Animal Ethics Committee of the Third Military Medical University. Nude mice with six-week-old were randomly divided into the experimental group and the control group with four animals in each group. Lung cancer cells with and without TET1 gene overexpression were harvested, and single-cell suspensions of $1 \times 10^{7}$ in $200 \mu \mathrm{L}$ of phosphate-buffered saline were injected into the right abdominal wall of the nude mice and assigned to the experimental 
group and the control group, respectively. From the first day of injection, the major diameter (D) and the minor diameter (d) of tumor volume were measured every 5 days with a vernier caliper. The formula ( $\mathrm{D} \times$ $d^{2}$ ) /2 was used to calculate the volume of the tumor. All mice were killed after one month. The tumors were surgically dissected, and were then embedded in paraffin for HE staining and immunohistochemistry analysis.

\section{Methylated DNA immunopreciption (MeDIP) and hydroxymethylated DNA immunopreciption (hMeDIP)}

According to the instructions of the EpiQuik ${ }^{\mathrm{TM}}$ methylated DNA immunoprecipitation kit (EpiGentek, USA) and EpiQuik ${ }^{\text {TM }}$ hydroxymethylated DNA immunoprecipitation kit (EpiGentek, USA), MeDIP and hMeDIP were performed to detect the level of methylation and hydroxymethylation in the promoter of genes. Briefly, $1 \mu \mathrm{g}$ of sonicated DNA was diluted and incubated with $150 \mu \mathrm{l}$ of antibody buffer at room temperature for 90 minutes in strip wells. For MeDIP, normal mouse IgG as the negative control and anti5 -mC for samples were added in the antibody buffer. For hMeDIP, non-Immune IgG was added to the negative control well, anti-5-hmC antibody was added to the sample wells and the positive control wells. Next, the wells were washed once with TE buffer. DNA release buffer containing proteinase $\mathrm{K}$ was added to the samples followed by reverse buffer. At last, Filter column was used to elute purified DNA. DNA was analyzed by qRT-PCR, and primer sequences were provided in Supplementary Table S3. All analyses were performed at least triplicate and repeated three times.

\section{Statistical analysis}

Statistical analysis was performed using SPSS 19.0 software (SPSS, Inc., Chicago, IL). Measurement data were expressed as the mean value \pm standard deviation (SD) and the significances among groups were analyzed using Student's $t$ test (normal distribution) or $F$ test. $P$ values less than 0.05 were considered statistically significant.

\section{Results}

\section{TET1 expression was down-regulated during 3-MCA induced lung carcinogenesis and human tumor samples}

Firstly, in order to detect the expression of TET1 gene during the process of chemical-induced lung carcinogenesis, TET1 expression of the 3-MCA-induced malignant transformation in HBE cell was detected by qRT-PCR (Fig. 1A) and Western blot (Fig. 1B). With the increase of 3-MCA treatment time, the mRNA and protein expression of TET1 gene gradually decreased significantly $(P<0.01)$. Then, qRT-PCR and Western blot was used to detect TET1 gene expression in the lung tissues of the 3-MCA-exposed rats in vivo. It was found that the mRNA (Fig. 1C) and protein (Fig. 1D) expression of TET1 gene was significantly down-regulated in precancerous tissues and cancer tissues compared to normal lung tissues in rats $(P<0.01)$. It further proved that 3-MCA exposure may result in down-regulation of TET1 gene. Next, the human lung cancer and adjacent normal tissue samples from lung cancer patients were used for 
immunostaining experiments. As shown in Fig. 1E and 1F, the expression level of TET1 gene in cancer tissues was significantly lower than that in adjacent normal lung tissues. These results suggested that TET1 gene may play an important role during the process of lung cancer.

\section{DNA methylation regulated the expression of TET1 during lung carcinogenesis}

In order to explore the epigenetic regulatory mechanism of TET1 gene, we firstly detected the methylation level of TET1 in 3-MCA-induced malignant transformation cells through MeDIP-qPCR. As shown in Fig. 2A, the methylation of TET1 in 3-MCA-exposed HBE cells was significantly up-regulation compared with the DMSO exposed HBE cells $(P<0.01)$. To demonstrate whether TET1 expression is regulated by DNA methylation, 3-MCA-exposed HBE cells were used for demethylation experiment. As shown in Fig. 2B, the methylation of TET1 in 5-aza-dC treated cells was significantly down-regulated compared with the DMSO group $(P<0.01)$. At the same time, the mRNA (Fig. 2C-D) and protein (Fig. 2E-F) expression levels of TET1 gene were significantly up-regulated after demethylation through RT-PCR and Western blot detection $(P<0.01)$. These results suggest that the expression of TET1 is regulated by DNA methylation during the 3-MCA-induced lung cancer.

\section{Overexpression of TET1 inhibits cell proliferation, migration and invasion}

To explore the role of TET1 gene during 3-MCA-induced lung cancer, the TET1 overexpression vector was constructed. We firstly examined TET1 mRNA expression in the lung cancer cell lines and normal HBE cell line by qRT-PCR. As shown in Supplementary Fig. 1, the TET1 transcript level was down-regulated in lung cancer cell lines, especially in SPC-A-1, but was readily expressed in the normal lung cell line HBE. Then, we chose SPC-A-1 with TET1 low expression as cell model for TET1 overexpression (Fig. 3A and Supplementary Fig. 2). CCK-8 assay found that after over-expressing TET1, the cell growth rate was significantly inhibited $(P<0.01)$ (Fig. 3B). Next, soft agar experiments and colony formation experiments were used to further verify the effect of over-expressing TET1 on cell growth. The results showed that the colony forming ability of the cells was significantly lower than that of the control group after overexpressing TET1 $(P<0.01)$ (Fig. 3C and 3D). Then, scratch healing experiments were used to detect the effect of over-expressing TET1 on cell migration ability. As shown in Fig. 3E, compared with the control group, the migration distance of cells was significantly reduced after overexpression of TET1 $(P<0.01)$. At the same time, transwell was used to detect the migration and invasion ability of cells after overexpressing TET1. The results showed that the number of cells crossing the membrane was significantly lower in the over-expressed TET1 group than that in the control group $(P<0.01)$ (Fig. 3F). The results above suggest that overexpression of TET1 can inhibit cell growth, migration and invasion.

\section{Knockdown of TET1 promotes cell proliferation, migration and invasion}


To further demonstrate that TET1 can inhibit cell growth, migration and invasion, TET1 knockdown expression vector was constructed. TET1 overexpression stably transfected cells were used to knock down TET1 expression. The efficiency of knocking down TET1 expression was shown in Fig. 4A and Supplementary Fig. 3. After knocking down TET1 expression, TET1 expression was significantly lower than the control group $(P<0.01)$. CCK-8 assay, soft agar experiments and colony formation experiments detected the cell growth after knocking down TET1 expression, and found that after knocking down TET1 expression, cell growth was significantly promoted $(P<0.01)$ (Fig. 4B-4D). Next, scratch healing experiment found that the migration distance of cells with TET1 knockdown was significantly higher than that of the control group $(P<0.01)$ (Fig. 4E). What's more, transwell results showed that the migration and invasion of knock down TET1 expressing cells were significantly up-regulated $(P<0.01)$ (Fig. 4F). These results further suggested that TET1 expression can inhibit cell growth, migration and invasion of lung cancer cells.

\section{Overexpression of TET1 inhibits cell proliferation in vivo}

To verify the effect of TET1 on the growth of lung cancer cells in vivo, TET1 overexpression stably transfected cells were used in nude mice tumor formation experiments. After 30 days, obviously tumor mass was formed subcutaneously in nude mice. As shown in Figs. $5 \mathrm{~A}$ and $5 \mathrm{~B}$, the volume of tumor mass formed in the over-expressed TET1 group was significantly lower than that of the control group $(P<0.01)$. What's more, the weight of the tumor mass in over-expressed TET1 group was significantly downregulated compared with the control group (Fig. 5C) $(P<0.01)$. These results suggested that the growth of over-expressed TET1 cells in vivo was significantly inhibited. In order to further demonstrate the effect of TET1 on lung cancer cells in vivo, TUNEL and Ki67 immunostainingin embedded sections of the nude mice tumors were performed. It can be found from the immunohistochemical results shown in Fig. 5D and $5 \mathrm{E}$ that the apoptosis was higher in the over-expressed TET1 group than that in the control group, and that the expression of Ki67 in the over-expressed TET1 group was lower than that in the control group. It reveals that over-expression of TET1 could promote the apoptosis and inhibit the proliferation of the lung cancer cells in vivo.

\section{TET1 plays a tumor suppressing role through BER signaling pathway in lung cancer}

To explore the mechanism of TET1 during the 3-MCA-induced lung cancer cells, some key genes of BER signaling pathway were detected by qRT-PCR and Western blot. As shown in Fig. 6A and 6C, the mRNA and protein expression of TET1 in the 3-MCA-exposed group were significantly lower than that in the control group $(P<0.01)$, meanwhile the mRNA and protein expression of OGG1, XRCC1, and APEX1 were significantly lower compared with the control group $(P<0.01)$. When TET1 was over-expressed, the mRNA and protein expression of OGG1, XRCC1, and APEX1 were significantly up-regulated (Fig. 6B and 6D) $(P<$ 0.01). When the expression of TET1 was knocked down, the mRNA and protein expression of OGG1, XRCC1, and APEX1 were significantly down-regulated (Fig. 6B and 6D) $(P<0.01)$. These results 
suggested that TET1 function as a tumor suppressor gene through the BER signaling pathway. In order to further explore the mechanism how TET1 regulates BER pathway, MeDIP-qPCR and hMeDIP-qPCR were performed. The methylation of the promoter region of OGG1, XRCC1, and APEX1 were significantly downregulated (Fig. 6E), and the hydroxymethylation were significantly up-regulated (Fig. 6G), when the expression of TET1 was over-expressed $(P<0.01)$. In addition, after knocking down TET1 expression, the methylation of OGG1, XRCC1, and APEX1 were significantly up-regulated (Fig. 6F), and the hydroxymethylation were significantly down-regulated (Fig. 6H). These results revealed that epigenetic modification played an important role during TET1-mediated BER pathway regulation in lung cancer.

\section{Knocking down of OGG1, XRCC1, and APEX1 can promote the cell growth, migration and invasion of lung cancer}

To demonstrate that whether the regulation of TET1 on the cell growth, invasion, and migration of lung cancer depends on the BER signaling pathway, the expression of OGG1, XRCC1, and APEX1 were knocked down while TET1 was overexpression in lung cancer cells. Firstly, soft agar assay and cloning formation experiment were performed to detect the cell growth. As shown in Fig. 7A and 7B, over-expressed TET1 resulted in the significantly down-regulation of cell growth compared with the control $(P<0.01)$. Compared to the TET1 over-expression group, the cell growth of TET1 and siOGG1, TET1 and siXRCC1, TET1 and siAPEX1, and TET1 and siBER (the combination of siOGG1, siXRCC1 and siAPEX1) group were significantly up-regulated $(P<0.01)$. What's more, the growth of TET1 and siBER group was significantly up-regulated compared with TET1 and siOGG1, TET1 and siXRCC1, and TET1 and siAPEX1, respectively. Next, scratch healing and transwell experiments were performed to detect the migration and invasion. Knocking down of OGG1, XRCC1, and APEX1 could promote the migration and invasion of lung cancer cells, and simultaneously knocking down of OGG1, XRCC1, and APEX1 is particularly effective (Fig. 7C and 7D). These results suggested that BER signaling pathway is required for the anti-tumorigenesis function of TET1 in lung cancer. Taken together, the above data demonstrated that TET1 inhibits cell growth, migration and invasion in lung cancer by repressing the BER pathway, via demethylation of the promoters of the BER key regulator OGG1, XRCC1, and APEX1.

\section{Discussion}

Accumulating evidence has discovered that TET1 played important roles in the occurrence and development of neoplastic diseases $[23,24]$. It has reported that overexpression of TET1 could significantly inhibit cell growth, migration and invasion of colon cancer and cervical cancer $[23,25,26]$. In addition, the recent study also found that TET1 involved in p53 mediated lung cancer cellular aging as an oncogene [27]. However, there are other studies showing that TET1 was down-regulated in lung cancer and related to high expression of immune markers and high infiltration of immune cells [28]. Therefore, the role and specific mechanism of TET1 during the process of lung cancer is not yet clear. In this study, we highlighted the importance of TET1 and BER pathway in lung cancer. 
Recent research has found that K-ras promotes DNA methylation and malignant transformation by inhibiting TET1 expression [29]. Recovery of TET1 expression can induce re-expression of tumor suppressor genes and inhibit malignant transformation of cells. These results suggest that TET1mediated DNA demethylation is a crucial link in K-ras-mediated malignant transformation [29]. Our results indicate that the expression of TET1 is significantly down-regulated in lung cancer cell lines, 3MCA-induced malignant transformed cells, animal exposure models, and clinical samples. It suggested that TET1 abnormal expression may be the core link and key factor as early biological event during chemical-induced lung carcinogenesis.

The oxidation of 5-mC by TET proteins to 5-hmC inhibits the binding of DNA methyl-binding proteins, and 5-hmC cannot be recognized by DNMT1, resulting in the loss of methylation markers through subsequent DNA replication cycles and the formation of new unmethylated cytosine derivatives in subchains [30, 31]. Studies have shown that DNMTs inhibitor can enhance the osteogenic differentiation potential of adipose-derived mesenchymal stem cells by promoting the expression of TET1 [32]. These results suggest that DNMT proteins compete functionally with TET1 proteins to bind DNA strands, and there may be competition or inhibition between them. In our study, we proved that TET1 is highly methylated through DNMTs, resulting in down-regulation of TET1 expression, thereby promoting the process of 3MCA-induced malignant transformation in HBE cells. However, whether there is corsstalk between DNMTs and TET1 during tumorigenesis needs further study.

It has been reported that TET1 can increase the level of hydroxymethylation and decrease the level of methylation by binding the promoter region of cell growth and apoptosis-related genes, and promote the level of gene expression, thus participating in the regulation of the growth and metastasis of cancer cells and stem cells [28, 33-35]. Microarray cluster analysis of human embryonic cancer cell lines showed that TET1 was mainly enriched in promoter regions of genes involved in cell proliferation, exercise, angiogenesis and DNA damage repair by mediating 5-hmC [36]. Increasing evidence suggested that TET1 is a tumor suppressor in many types of cancer [23,26,37-39]. These reports can further confirm our results. However, there are several reports indicating that TET1 may function as an oncogene by mediating hypomethylation upon targeting by partner proteins in different cancers $[27,40]$. Recent study showed that TET1 protein can interact with specific partners and play a biological role through its catalytic and noncatalytic domains [41]. We speculated that the possible explanation for the distinct roles of TET1 is different upstream regulation factors in specific status and different interacting partners in specific cell type.

BER pathway is an indispensable DNA repair pathway that involves maintaining genome stability and thus preventing a series of human disease. BER plays a critical role in transcriptional regulation during epigenetic reprogramming [13]. DNA demethylation can passively occur through DNA replication, or it can actively occur with DNA replication-independent [42-44]. Activation of DNA methylation may involve TETs mediated oxidation of the methyl group, or activation-induced deaminase mediated deamination of methylated or nearby bases, and the modified nucleotide is replaced by the BER pathway [45]. Our study suggested that TET1 inhibits cell growth, migration and invasion by mediating DNA hydroxymethylation

Page $12 / 26$ 
to activate BER pathway during the process of chemically induced lung cancer. Previous studies have shown that genetic alteration and protein posttranslational modifications have emerged as important contributors in regulating the BER pathway through controlling cellular BER protein levels, protein-protein interactions, and enzymatic activities $[12,46]$. Our study focused on the level of transcriptional regulation to explore the regulatory mechanism of BER pathway during the process of lung cancer. It further enriches the role and importance of BER pathway regulation in a series of diseases including tumorigenesis. It has reported that TET1 plays a biological role in regulating BER pathway through protein-protein interaction [14]. Our results suggested that TET1 plays an anti-tumor role through transcriptional regulation of key molecules in BER pathway. This further enriched and supplemented the regulation mode of TET1 in different physiological and pathological states.

\section{Conclusion}

We clarified for the first time that TET1 down-regulated associated with DNA methylation and acted as a novel tumor suppressor that inhibited cell growth and metastasis through BER pathway in lung cancer. TET1 regulated the level of hydroxymethylation and methylation in the promoter region of key gene in BER pathway, which participates in the whole process of lung cancer induced by environmental chemicals. Our study is not only of great significance to elucidate the pathogenesis of chemical carcinogenesis and lung cancer, but also provides a scientific basis for searching for early biomarkers of environmental chemical carcinogenesis and prevention strategies.

\section{Abbreviations}

3-MCA, 3-methylcholanthrene; 5-aza-dC, 5-aza-2'-deoxycytidine; 5-hmC, 5-hydroxymethylcytosine; 5-mC, 5methylcytosine; BER, base excision repair; hMeDIP, hydroxymethylated DNA immunopreciption; MeDIP, Methylated DNA immunopreciption; RT-PCR, reverse transcription-polymerase chain reaction; TET, Teneleven translocation.

\section{Declarations}

\section{Ethics approval and consent to participate}

All procedures of the study were approved by the Animal Care Committee of Third Military Medical University and carried out instrict compliance with the relevant guidelines.

\section{Consent for publication}

All authors read the final approval manuscript and agreed for publication. 


\section{Availability of data and materials}

The datasets used and/or analysed during the current study are available from the corresponding author on reasonable request.

\section{Competing interests}

The authors declare that there are no conflicts of interest.

\section{Funding}

This work was supported by grants from the National Natural Science Foundation of China (No. 81573114 and 81872659) and the Natural Science Foundation Project of Chongqing CSTC of China (No. cstc2018jcyjAX0233).

\section{Authors' contributions}

HQC WBL and JYL conceived the study; HQC and WBL designed the experiments; HQC, DJC, YL, WBY, JF, $\mathrm{ZZ}, \mathrm{FH}, \mathrm{XJ}$, JPC, DDW carried out experiments; HQC and WBL analyzed the data, interpreted the data and wrote the manuscript; WBL, JC and JYL supervised the study and finalized the manuscript.

\section{Acknowledgements}

We sincerely thank Yajing Li for technical help.

\section{References}

1. Siegel RL, Miller KD, Jemal A. Cancer statistics. 2020. CA Cancer J Clin. 2020. 70(1): 7-30.

2. He XZ, Chen W, Liu ZY, Chapman RS. An epidemiological study of lung cancer in xuan wei county, china: current progress. Case-control study on lung cancer and cooking fuel. Environ Health Perspect. 1991;94:9-13.

3. Venkatesh HN, Jeru Manoj M, Ghosh D, Chetan GK. Environmental pollutants leading to carcinogenesis: process of natural selection of human cells due to chronic inflammation and sustained stress environment. Int J Environ Sci Tech. 2015;12(7):2415-26.

4. Belinsky SA. Unmasking the lung cancer epigenome. Annu Rev Physiol. 2015;77:453-74.

5. Li E, Zhang Y. DNA methylation in mammals. Cold Spring Harb Perspect Biol. 2014;6(5):a019133.

6. Cavalli G, Heard E. Advances in epigenetics link genetics to the environment and disease. Nature. 2019;571(7766):489-99. 
7. Feil R, Fraga MF. Epigenetics and the environment: emerging patterns and implications. Nat Rev Genet. 2012;13(2):97-109.

8. Ladd-Acosta C, Fallin MD. The role of epigenetics in genetic and environmental epidemiology. Epigenomics. 2016;8(2):271-83.

9. Huang Y, Rao A. Connections between TET proteins and aberrant DNA modification in cancer. Trends Genet. 2014;30(10):464-74.

10. Melamed P, Yosefzon Y, David C, Tsukerman A, Pnueli L. Tet Enzymes, Variants, and Differential Effects on Function. Front Cell Dev Biol. 2018;6:22.

11. Wu HX, Chen YX, Wang ZX, Zhao Q, He MM, Wang YN, Wang F, Xu RH. Alteration in TET1 as potential biomarker for immune checkpoint blockade in multiple cancers. J Immunother Cancer. 2019;7(1):264.

12. Carter RJ, Parsons JL. Base excision repair: a pathway regulated by post-translational modifications. Mol Cell Biol. 2016;36(10):1426-37.

13. Wallace SS. Base excision repair: a critical player in many games. DNA Repair. 2014;19:14-26.

14. Okashita N, Kumaki Y, Ebi K, Nishi M, Okamoto Y, Nakayama M, Hashimoto S, Nakamura T, Sugasawa K, Kojima N, Takada T, Okano M, Seki Y. PRDM14 promotes active DNA demethylation through the Ten-eleven translocation (TET)-mediated base excision repair pathway in embryonic stem cells. Development. 2014;141(2):269-80.

15. Müller U, Bauer C, Siegl M, Rottach A, Leonhardt H. TET-mediated oxidation of methylcytosine causes TDG or NEIL glycosylase dependent gene reactivation. Nucleic Acids Res. 2014;42(13):8592-604.

16. Chen HQ, Zhao J, Li Y, He LX, Huang YJ, Shu WQ, Cao J, Liu WB, Liu JY. Gene expression network regulated by DNA methylation and microRNA during microcystin-leucine arginine induced malignant transformation in human hepatocyte L02 cells. Toxicol Lett. 2018;289:42-53.

17. Ho D, Gill K, Fahl WE. Benz[a]anthracene and 3-methylcholanthrene induction of cytochrome P-450 in C3H/10T1/2 mouse fibroblasts. Mol Pharmacol. 1983;23(1):198-205.

18. Sotiropoulou M, Pappas P, Marselos M. Effects of 3-methylcholanthrene and aspirin coadministration on ALDH3A1 in HepG2 cells. Chem Biol Interact. 2001, 130-132(1-3): 235-245.

19. Liu WB, Liu JY, Ao L, Zhou ZY, Zhou YH, Cui ZH, Yang H, Cao J. Dynamic changes in DNA methylation during multistep rat lung carcinogenesis induced by 3-methylcholanthrene and diethylnitrosamine. Toxicol Lett. 2009;189(1):5-13.

20. Liu WB, Han F, Du XH, Jiang X, Li YH, Liu Y, Chen HQ, Ao L, Cui ZH, Cao J, Liu JY. Epigenetic silencing of Aristaless-like homeobox-4, a potential tumor suppressor gene associated with lung cancer. Int J Cancer. 2014;134(6):1311-22.

21. Liu WB, Han F, Jiang X, Yin L, Chen HQ, Li YH, Liu Y, Cao J, Liu JY. Epigenetic regulation of ANKRD18B in lung cancer. Mol Carcinog. 2015;54(4):312-21.

22. Chen HQ, Zhao J, Li Y, Huang YJ, Chen DJ, He LX, Wang LQ, Zheng CF, Wang J, Cao J, Shu WQ, Liu JY, Liu WB. Epigenetic inactivation of LHX6 mediated microcystin-LR induced hepatocarcinogenesis 
via the Wnt/B-catenin and P53 signaling pathways. Environ Pollut. 2019;252(Pt A):216-26.

23. Su PH, Hsu YW, Huang RL, Chen LY, Chao TK, Liao CC, Chen CW, Wu TI, Mao SP, Balch C, Lai HC. TET1 promotes $5 \mathrm{hmC}$-dependent stemness, and inhibits a $5 \mathrm{hmC}$-independent epithelialmesenchymal transition, in cervical precancerous lesions. Cancer Lett. 2019;450:53-62.

24. Wu J, Li H, Shi M, Zhu Y, Ma Y, Zhong Y, Xiong C, Chen H, Peng C. TET1-mediated DNA hydroxymethylation activates inhibitors of the Wnt/ $\beta$-catenin signaling pathway to suppress EMT in pancreatic tumor cells. J Exp Clin Cancer Res. 2019;38(1):348.

25. Guo H, Zhu H, Zhang J, Wan B, Shen Z. TET1 suppresses colon cancer proliferation by impairing repressing inhibitors of the wnt pathway. Oncogene. 2019;120(8):12559-65.

26. Neri F, Dettori D, Incarnato D, Krepelova A, Rapelli S, Maldotti M, Parlato C, Paliogiannis P, Oliviero S. TET1 is a tumour suppressor that inhibits colon cancer growth by derepressing inhibitors of the wnt pathway. Oncogene. 2015;34(32):4168-76.

27. Filipczak PT, Leng S, Tellez CS, Do KC, Grimes MJ, Thomas CL, Walton-Filipczak SR, Picchi MA, Belinsky SA. p53-Suppressed Oncogene TET1 Prevents Cellular Aging in Lung Cancer. Cancer Res. 2019;79(8):1758-68.

28. Collignon E, Canale A, Al Wardi C, Bizet M, Calonne E, Dedeurwaerder S, Garaud S, Naveaux C, Barham W, Wilson A, Bouchat S, Hubert P, Van Lint C, Yull F, Sotiriou C, Willard-Gallo K, Noel A, Fuks F. Immunity drives TET1 regulation in cancer through NF-KB. Sci Adv. 2018;4(6):eaap7309.

29. Wu BK, Brenner C. Suppression of TET1-dependent DNA demethylation is essential for KRASmediated transformation. Cell Rep. 2014;9(5):1827-40.

30. Ito S, D'Alessio AC, Taranova OV, Hong K, Sowers LC, Zhang Y. Role of Tet proteins in $5 \mathrm{mC}$ to $5 \mathrm{hmC}$ conversion, ES-cell self-renewal and inner cell mass specification. Nature. 2010;466(7310):1129-33.

31. Ito S, Shen L, Dai Q, Wu SC, Collins LB, Swenberg JA, He C, Zhang Y. Tet proteins can convert 5methylcytosine to 5-formylcytosine and 5-carboxylcytosine. Science. 2011;333(6047):1300-3.

32. Yan X, Ehnert S, Culmes M, Bachmann A, Seeliger C, Schyschka L, Wang Z, Rahmanian-Schwarz A, Stöckle U, De Sousa PA, Pelisek J, Nussler AK. 5-azacytidine improves the osteogenic differentiation potential of aged human adipose-derived mesenchymalstem cells by DNA demethylation. PLoS One. 2014;9(6):e90846.

33. Mahaira LG, Katsara O, Pappou E, lliopoulou EG, Fortis S, Antsaklis A, Fotinopoulos P, Baxevanis CN, Papamichail M, Perez SA. IGF2BP1 expression in human mesenchymal stem cells significantly affects their proliferation and is under the epigenetic control of TET1/2 demethylases. Stem Cells Dev. 2014;23(20):2501-12.

34. Navarro A, Yin P, Ono M, Monsivais D, Moravek MB, Coon JS, Dyson MT, Wei JJ, Bulun SE. 5Hydroxymethylcytosine promotes proliferation of human uterine leiomyoma: a biological link to a new epigenetic modification in benign tumors. J Clin Endocrinol Metab. 2014;99(11):E2437-45.

35. Xin YJ, Yuan B, Yu B, Wang YQ, Wu JJ, Zhou WH, Qiu Z. Tet1-mediated DNA demethylation regulates neuronal cell death induced by oxidative stress. Sci Rep. 2015;5:7645. 
36. Putiri EL, Tiedemann RL, Thompson JJ, Liu C, Ho T, Choi JH, Robertson KD. Distinct and overlapping control of 5-methylcytosine and 5-hydroxymethylcytosine by the TET proteins in human cancer cells. Genome Biol. 2014;15(6):R81.

37. Cimmino L, Dawlaty MM, Ndiaye-Lobry D, et al. TET1 is a tumor suppressor of hematopoietic malignancy. Nat Immunol. 2015;16(6):653-62.

38. Chen LY, Huang RL, Chan MW, et al. TET1 reprograms the epithelial ovarian cancer epigenome and reveals casein kinase $2 a$ as a therapeutic target. J Pathol. 2019;248(3):363-76.

39. Fan J, Zhang Y, Mu J, et al. TET1 exerts its anti-tumor functions via demethylating DACT2 and SFRP2 to antagonize Wnt/ $\beta$-catenin signaling pathway in nasopharyngeal carcinoma cells. Clin Epigenetics. 2018;10(1):103.

40. Good CR, Panjarian S, Kelly AD, et al. TET1-Mediated Hypomethylation Activates Oncogenic Signaling in Triple-Negative Breast Cancer. Cancer Res. 2018;78(15):4126-37.

41. Singh AK, Zhao B, Liu X, et al. Selective targeting of TET catalytic domain promotes somatic cell reprogramming. Proc Natl Acad Sci U S A. 2020;117(7):3621-6.

42. Kagiwada S, Kurimoto K, Hirota T, Yamaji M, Saitou M. Replication coupled passive DNA demethylation for the erasure of genome imprints in mice. EMBO J. 2013;32(3):340-53.

43. Ohno R, Nakayama M, Naruse C, Okashita N, Takano O, Tachibana M, Asano M, Saitou M, Seki Y. A replication-dependent passive mechanism modulates DNA demethylation in mouse primordial germ cells. Development. 2013;140:2892-903.

44. Wu SC, Zhang Y. Active. DNA demethylation: many roads lead to Rome. Nat Rev Mol Cell Biol. 2010;11(9):607-20.

45. Bochtler M, Kolano A, Xu GL. DNA demethylation pathways: additional players and regulators. Bioessays. 2017;39(1):1-13.

46. D'Errico M, Parlanti E, Pascucci B, et al. Single nucleotide polymorphisms in DNA glycosylases: From function to disease. Free Radic Biol Med. 2017;107:278-91.

\section{Figures}


Chen at al Figure 1 A-F

A

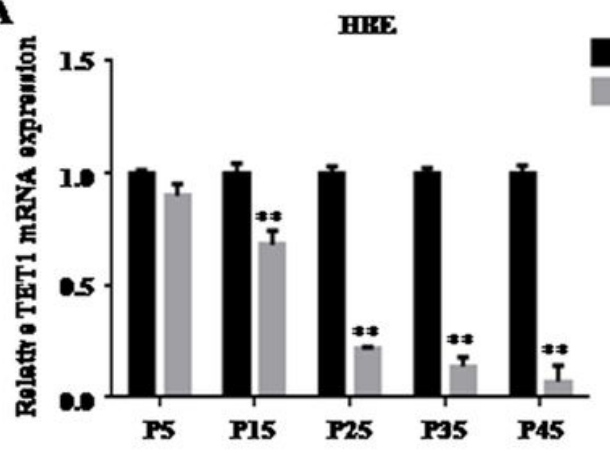

C

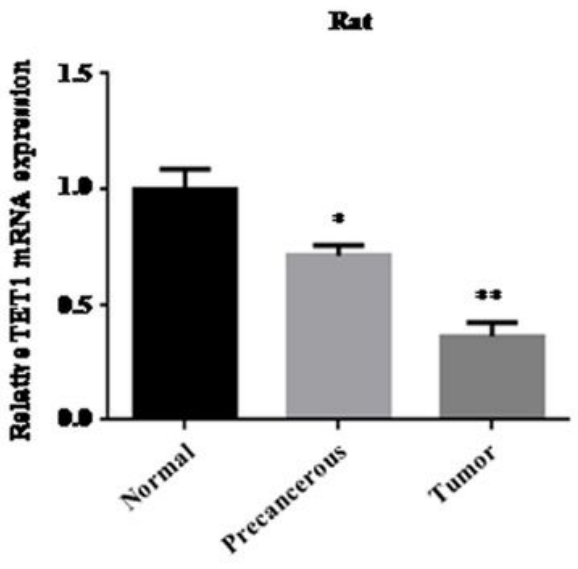

$\mathbf{E}$

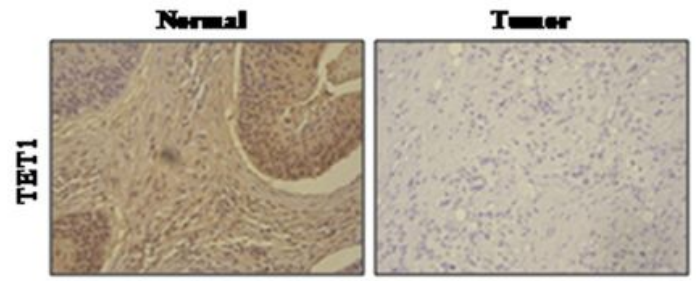

B

Daso

3MCA
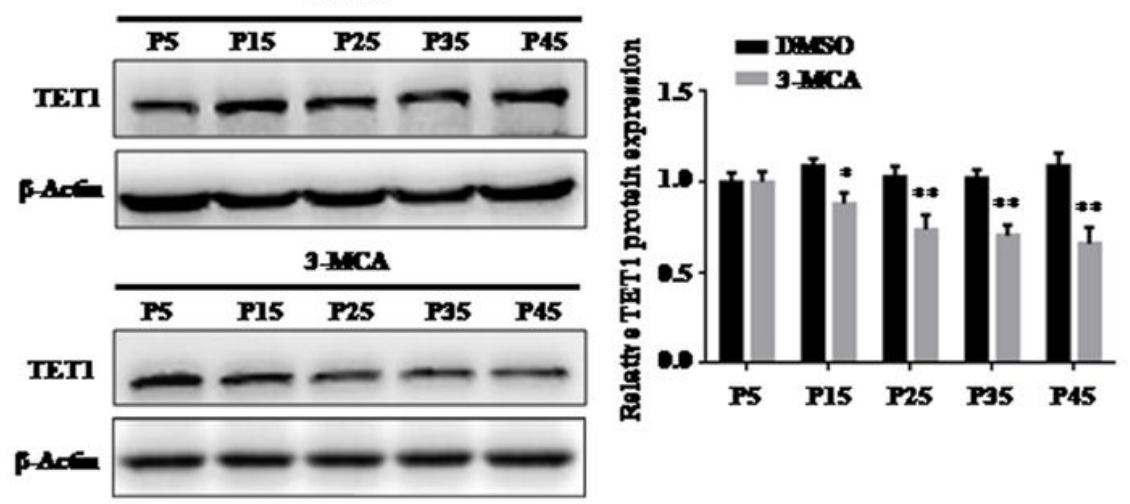

D
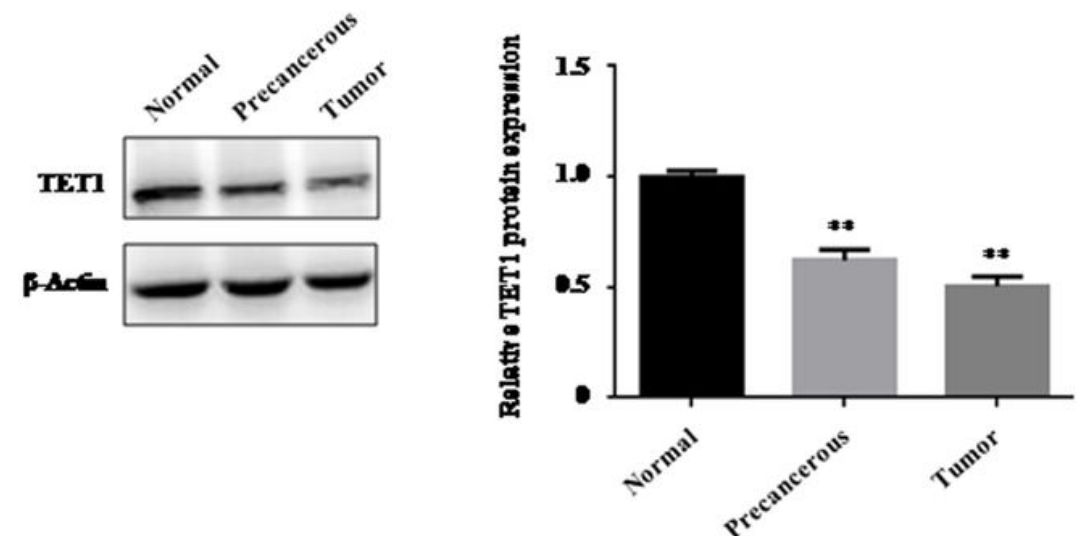

F

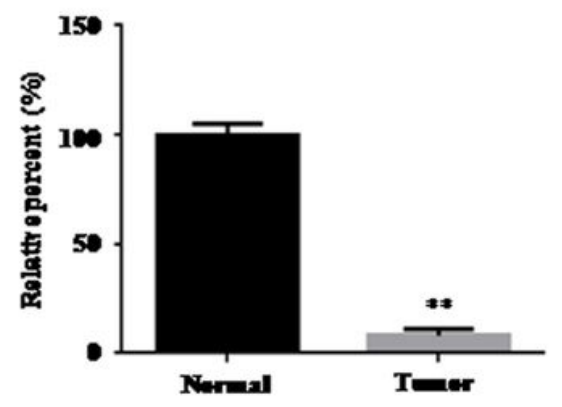

Figure 1

The mRNA and protein expression level of TET1 was significantly downregulated during 3-MCA-induced lung cancer. A. Quantitative RT-PCR was used to detect the mRNA expression of TET1 during the process of malignant transformation in HBE cells induced by 3-MCA. TET1 mRNA expression down-regulated in 3MCA-induced malignantly transformed HBE cells on the 5th, 15th, 25th, 35th, and 45th passages and named as P5, P15, P25, P35, and P45. B. Immunoblotting to measure the protein expression of TET1 in HBE cells during malignant transformation induced by 3-MCA. C. TET1 mRNA expression during chemical-induced rat lung cancer model. D. TET1 protein expression during chemical-induced rat lung 
cancer model. E. Immunohistochemistry was used to measure the protein expression of TET1 in tumor and adjacent normal tissues of lung cancer patients. F. Quantitative expression of TET1 protein in tumor and adjacent tissues. ${ }^{*} \mathrm{P}<0.05,{ }^{* *} \mathrm{P}<0.01$.

\section{Chen at al Figure 2A-F}

$\mathbf{A}$

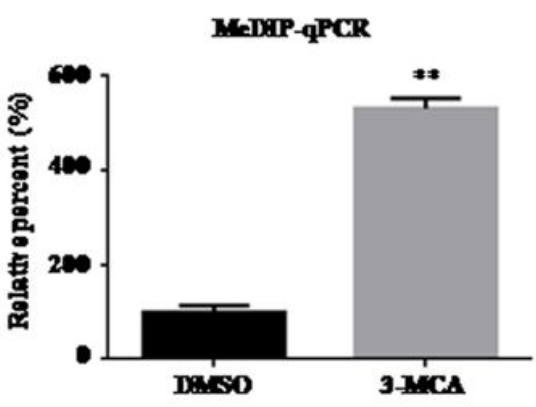

C

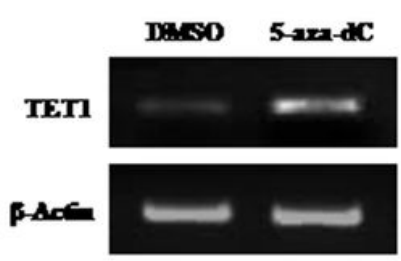

$\mathbf{E}$

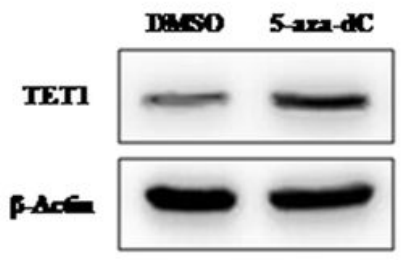

B

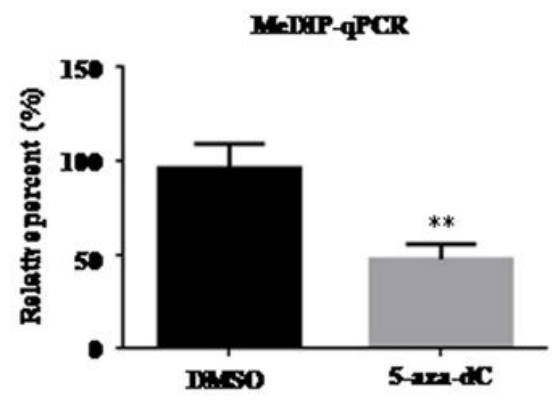

D

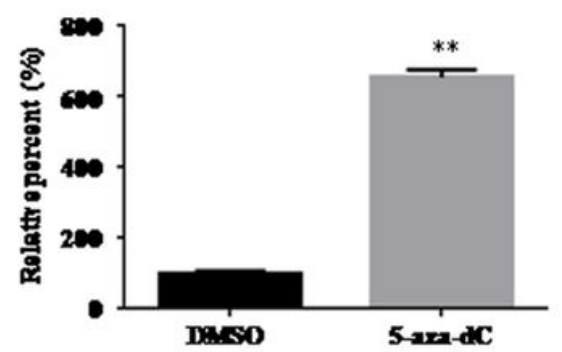

$\mathbf{F}$

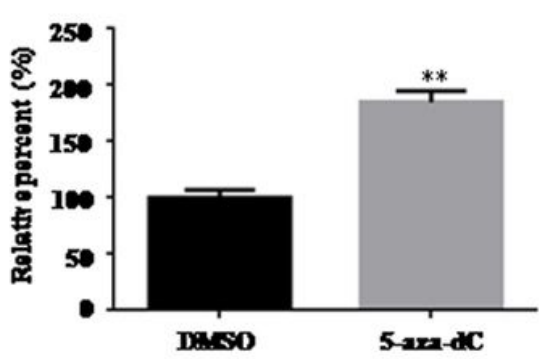

Figure 2

Downregulation of TET1 expression was regulated by DNA methylation during 3-MCA-induced lung carcinogenesis. A. Methylation analysis of TET1 gene was detected by MeDIP-qPCR during 3-MCA induced malignant transformation in HBE cells. B. The methylation level of TET1 gene was detected by MeDIP-qPCR after treatment with demethylation agent 5-aza-dC. C and D. The change of TET1 gene 
mRNA levels was detected by qRT-PCR after 5-aza-dC treatment. E and F. The protein expression of TET1 was measured by Western blot after 5-aza-dC treatment. ** $\mathrm{P}<0.01$.

\section{Chen at al Figure 3 A-F}

$\mathbf{A}$
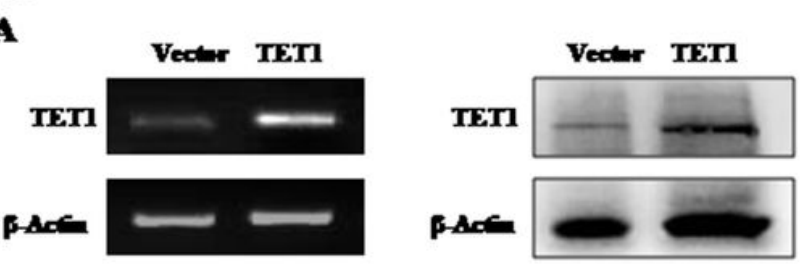

B

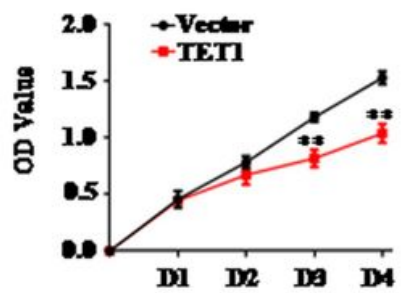

C

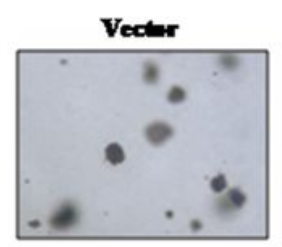

TETI

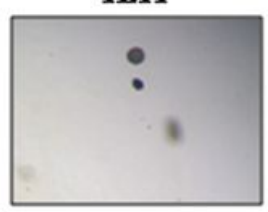

D
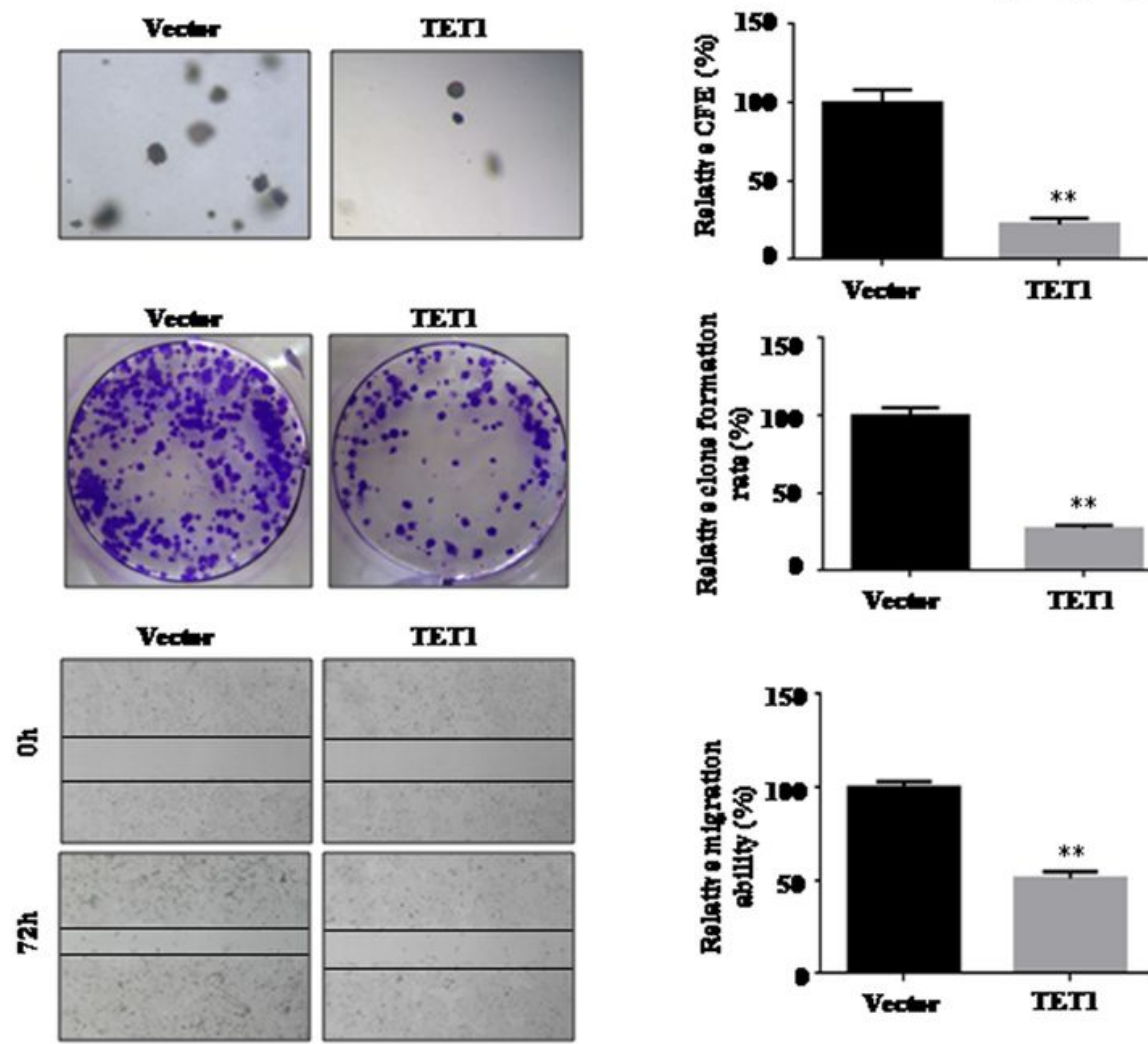

TETI
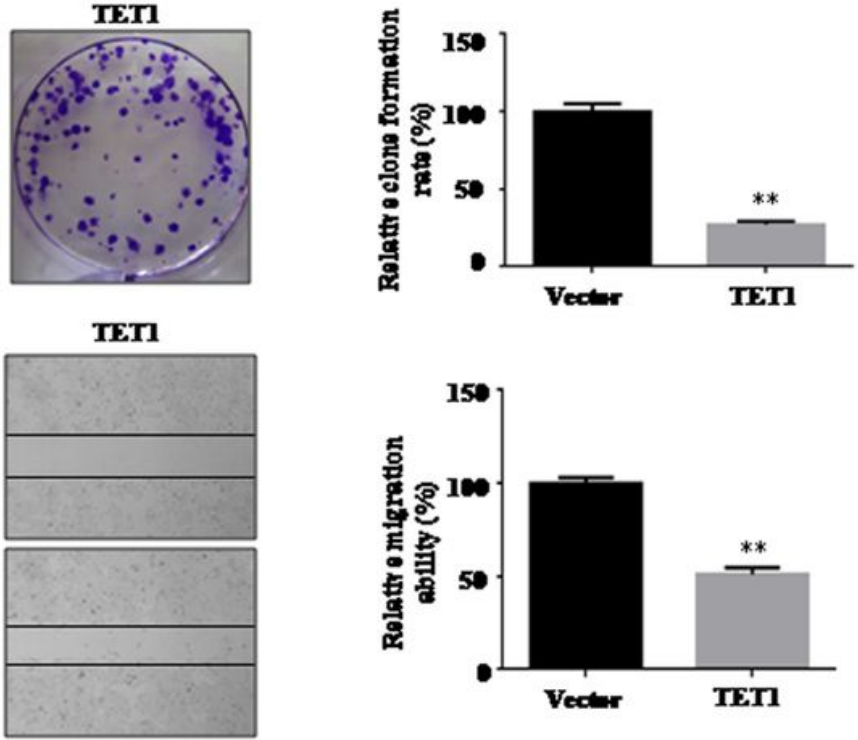

$\mathbf{F}$
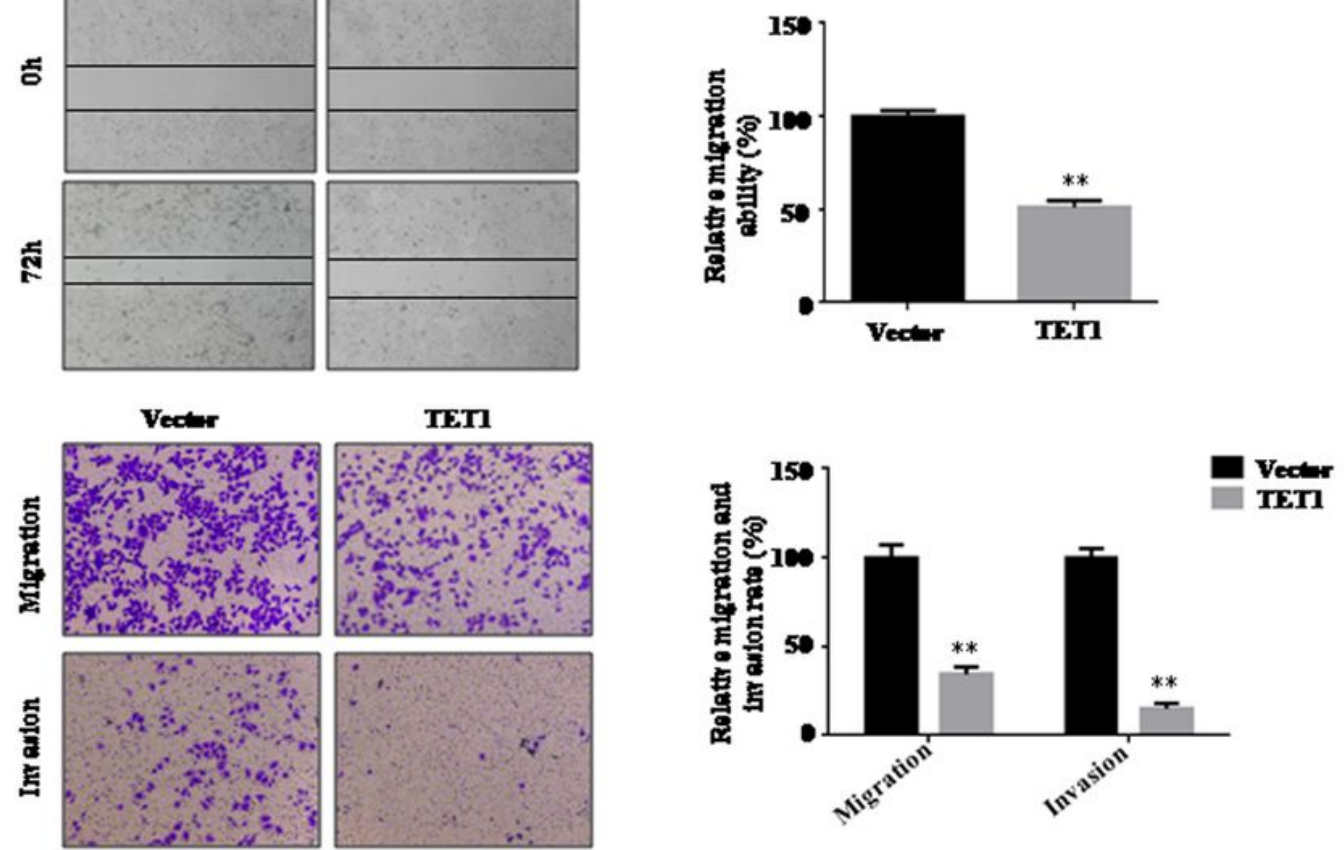

Figure 3

Overexpression of TET1 gene inhibited proliferation, migration and invasion of lung cancer cells. A. The transfection efficiency of TET1 overexpression was determined by qRT-PCR (left panel) and Western blot (right panel). The results showed that the TET1 gene was successfully overexpressed in lung cancer cells. B. CCK-8 assay was used to detect the effect of TET1 overexpression on lung cancer cell growth. C. Soft agar colony formation assay was used to detect the growth capability of lung cancer cells transfected 
with control or TET1-expressing vector. D. Colony formation assay was used to detect the colony formation capability of lung cancer cells transfected with control (left panel) or TET1 (right panel). E. Scratch healing pattern and relative mobility quantification of lung cancer cells after overexpression of TET1 gene. F. Overexpression of TET1 inhibited the migration and invasion of lung cancer cells by Transwell assay.

\section{Chen at al Figure 4A-F}

$\mathbf{A}$
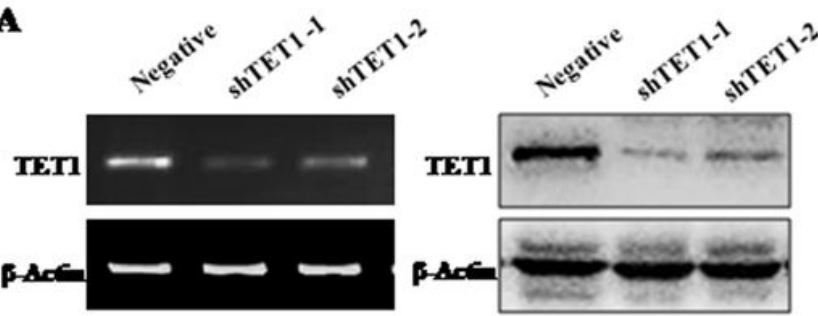

C

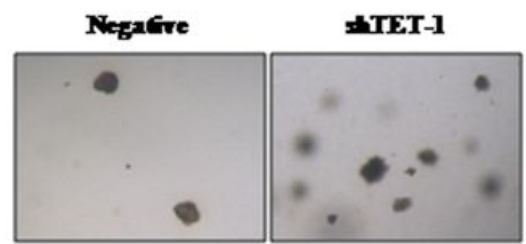

D

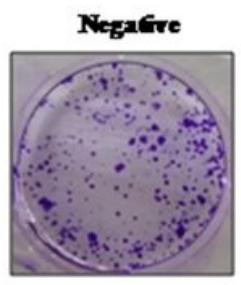

$\mathbf{E}$
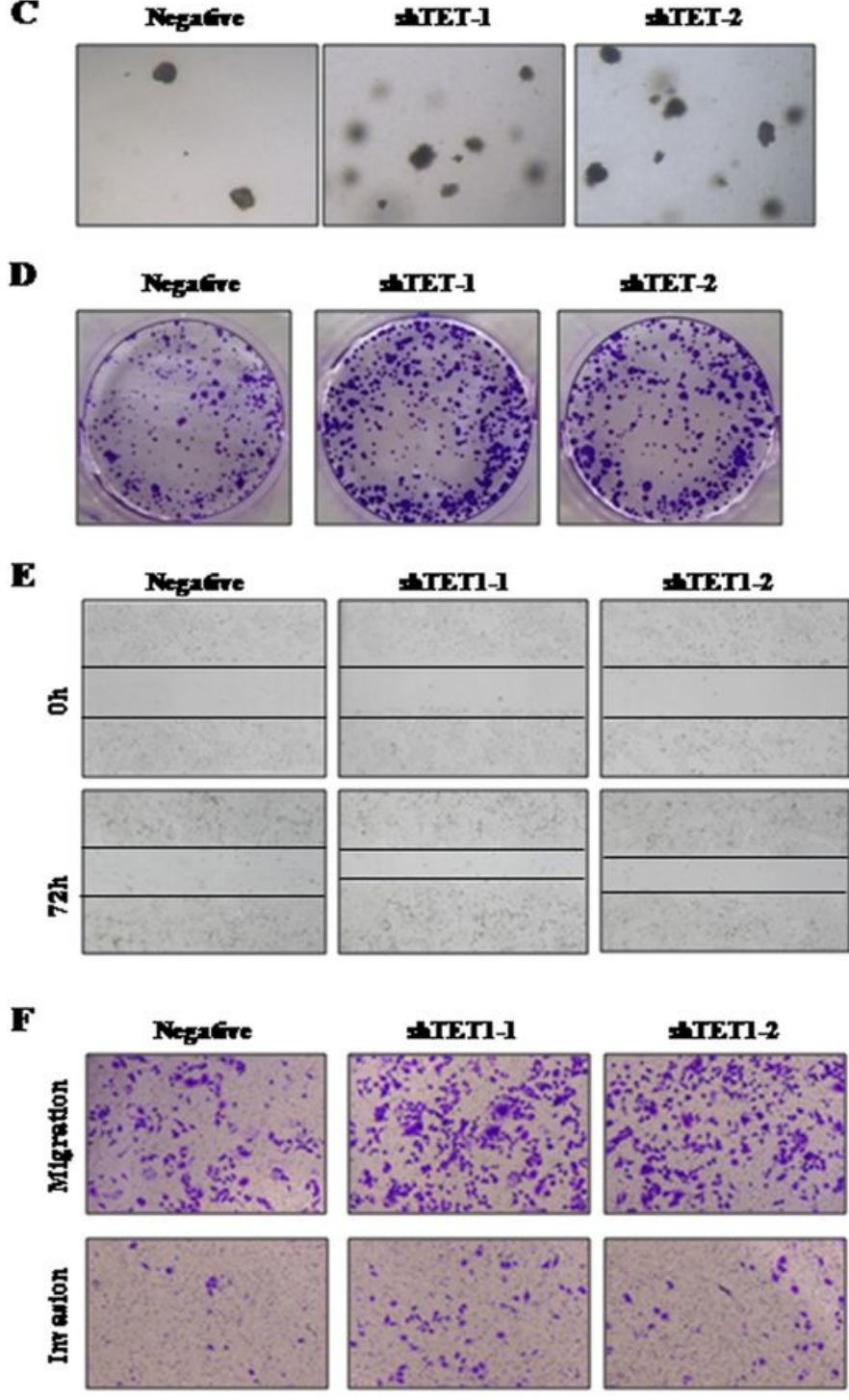

जTET1-1
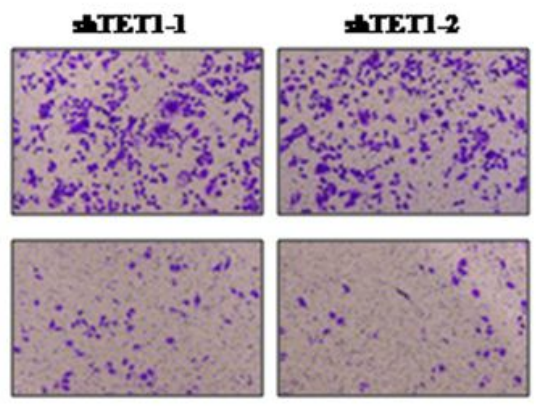

B
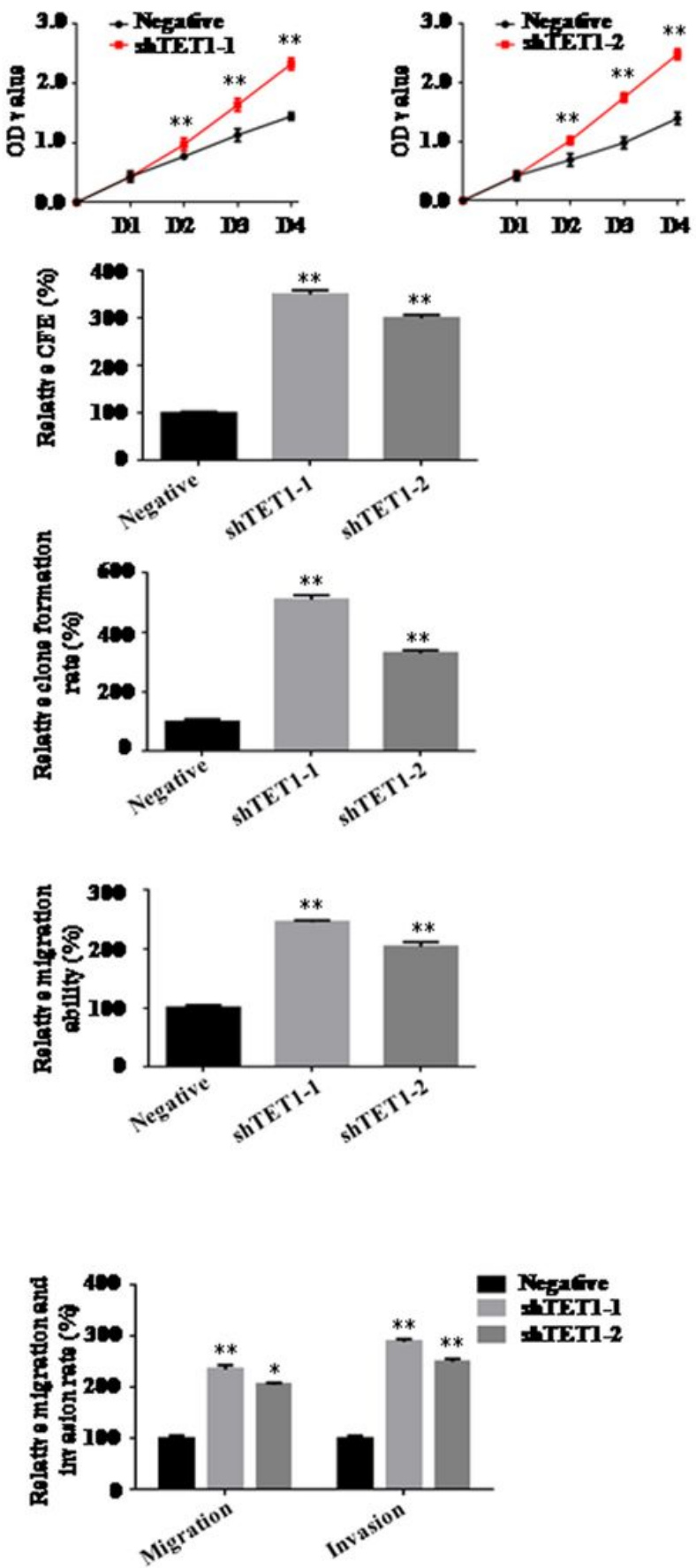

Figure 4

Knockdown of TET1 gene promoted proliferation, migration and invasion of lung cancer cells. A. Knockdown efficiency of TET1 mRNA and protein level was determined by qRT-PCR (left panel) and 
Western blot (right panel). B. CCK-8 assay was performed for growth curve of lung cancer cells transfected with control and shTET1 vectors. C. Soft agar assay was used to detect the proliferation of lung cancer cells after the expression of TET1 gene was knocked down. D. Clone formation assay was performed for detecting the proliferation of lung cancer cells after knockdown of TET1 gene expression. E. Relative mobility of lung cancer cells was detected by scratch healing experiments after knocking down the expression of TET1 gene. F. Transwell assay was used to detect the migration and invasion of lung cancer cells after knocking down the expression of TET1 gene. The data were expressed as the mean \pm SD of three independent experiments. ${ }^{*} P<0.05,{ }^{*} P<0.01$. 
Chen at at Figure 5A-E

$\mathbf{A}$
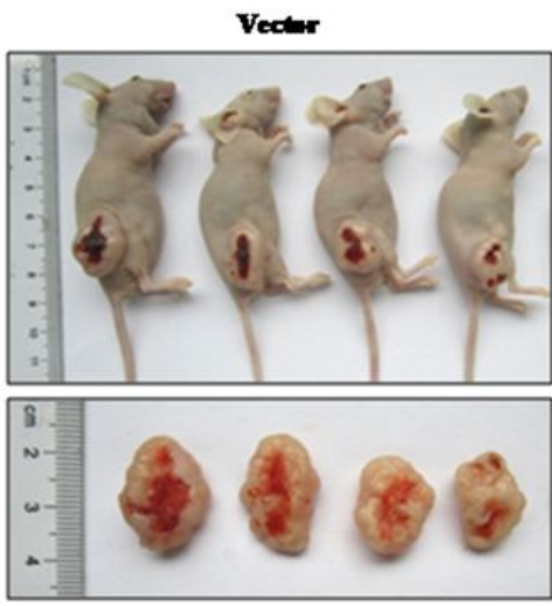

B

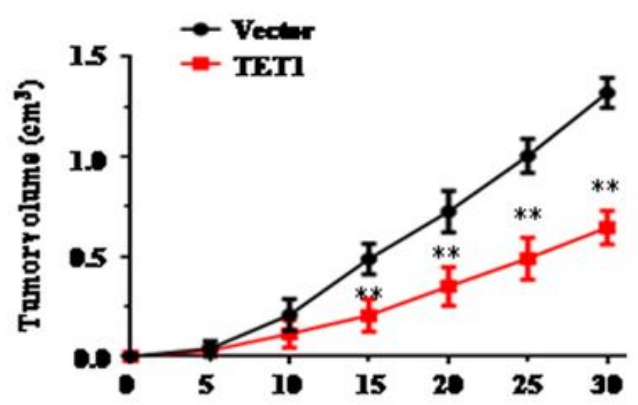

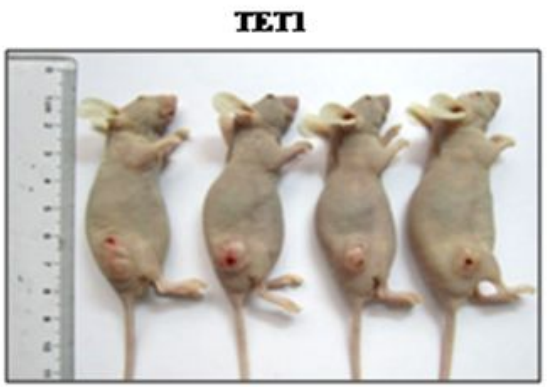

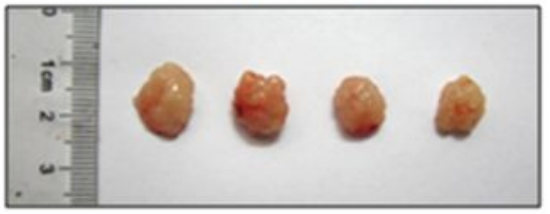

C

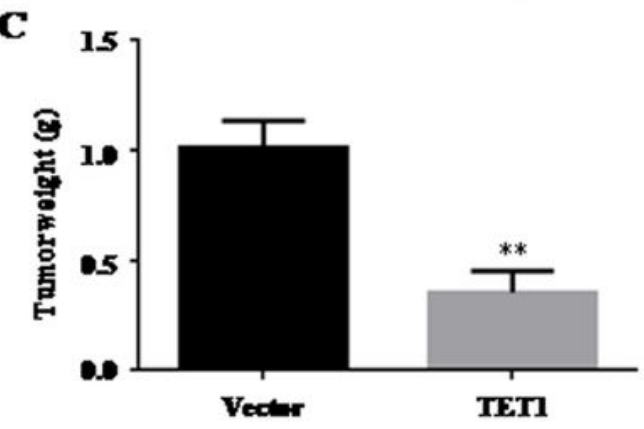

TETI

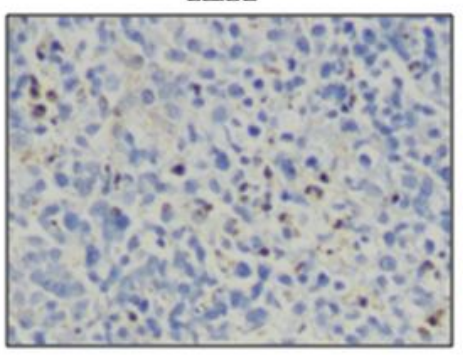

TET1

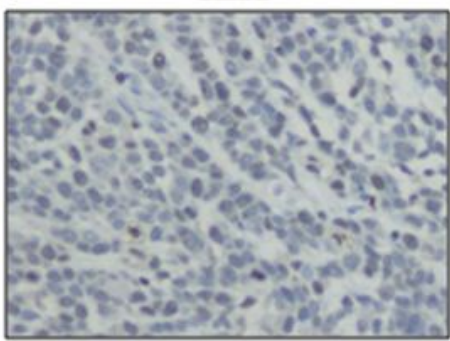

\section{Figure 5}

Overexpression of TET1 gene inhibited the growth of lung cancer cells in nude mice. A. The growth of tumors after subcutaneous injection of lung cancer cells with TET 1 overexpresssion for 30 days in nude mice. Representative images of tumor volumes from xenograft mice described above. B. The growth of tumor was observed every 5 days after subcutaneous injection of cells with or without expressing TET1 gene. C. After the tumor was removed, the weight of the tumor was calculated. The data are shown as the 
means \pm S.D. D. Representative images of apoptosis detection in tumor sections from xenograft mice by TUNEL. E. Representative images of immunohistochemistry staining for cell proliferation test (Ki67) in tumor sections from xenograft mice described above. * $\mathrm{P}<0.05$, ** $\mathrm{P}<0.01$.

\section{Chen et al Figure 6A-H}

$\mathbf{A}$

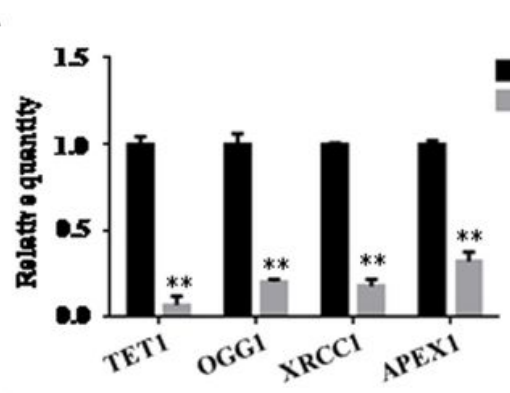

C

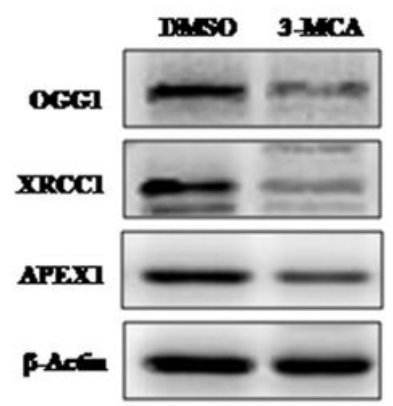

$\mathbf{E}$

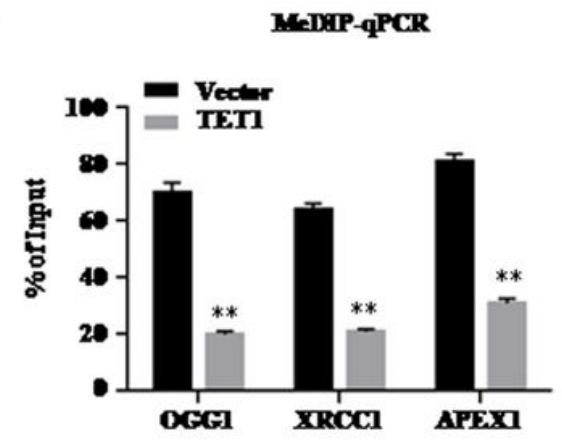

G

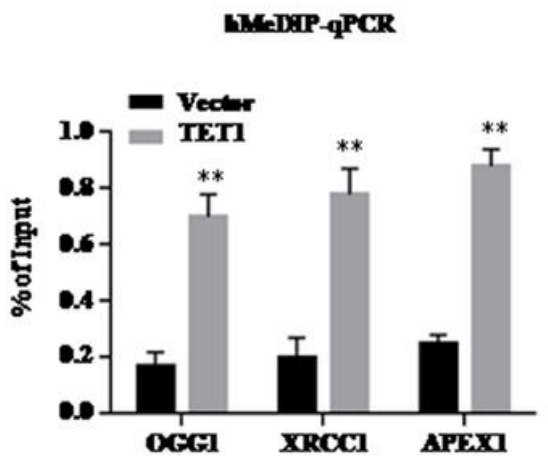

B

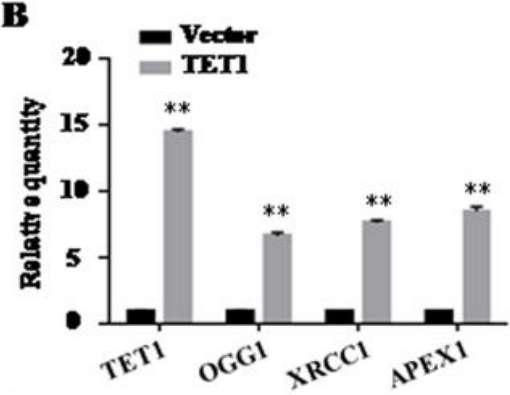

D
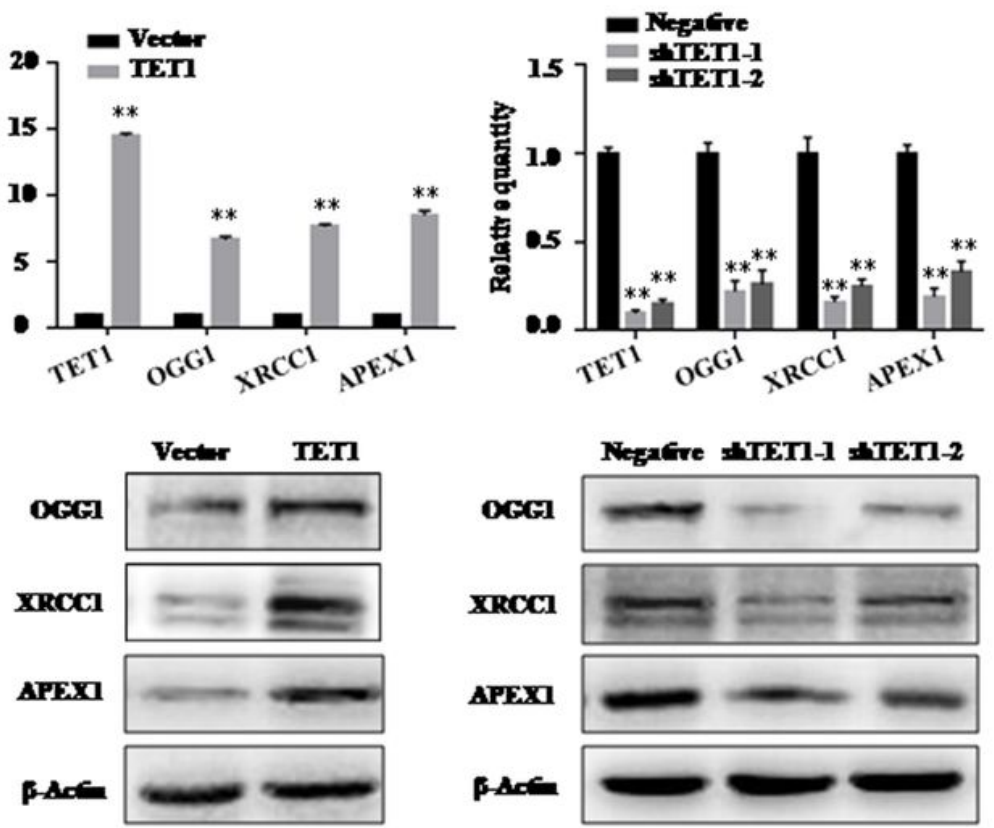

$\mathbf{F}$

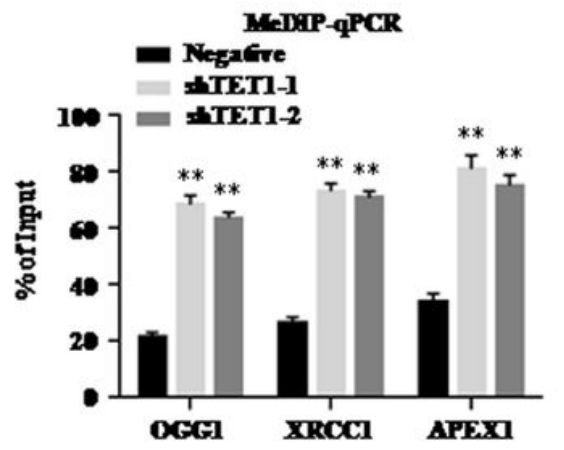

$\mathbf{H}$

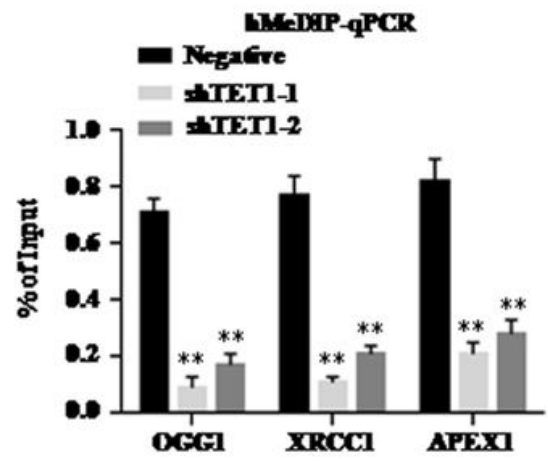

Figure 6

TET1 regulated the key genes of BER pathway through hydroxymethylation modification during lung carcinogenesis. A. Detection of the mRNA expression level of the key genes (OGG1, XRCC1, APEX1) of BER pathway during the process of cell malignant transformation induced by 3-MCA. B. The mRNA expression level of key genes (OGG1, XRCC1, APEX1) in BER pathway was detected after overexpression 
of TET1 and knockdown of TET1. C. Detection of protein expression level of key gene of BER pathway during the process of 3-MCA induced malignant transformation in HBE cells. D. Protein expression level of key genes in BER pathway after TET1 overexpression and knockdown. E and F. The methylation level of key genes in BER pathway was detected by MeDIP-qPCR after TET1 overexpression (E) and knockdown $(F) . G$ and $H$. the level of hydroxymethylation of the key gene of BER pathway was detected by hMeDIP-qPCR after overexpression $(\mathrm{G})$ and knockdown $(\mathrm{H})$ of TET1. ** $\mathrm{P}<0.01$.

\section{Chen at al Figure $7 A-D$}

$\mathbf{A}$

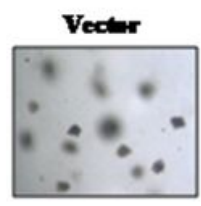

TET
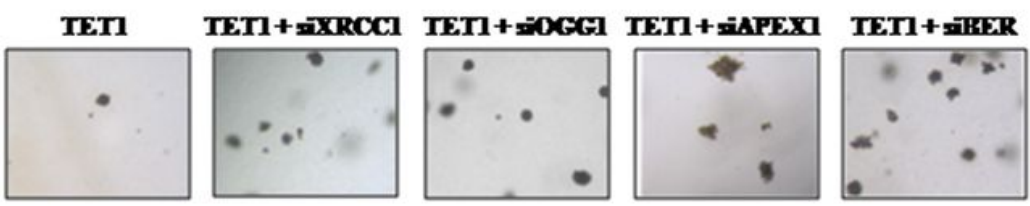

B

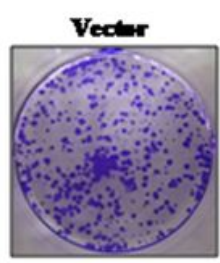

TETI

TET1 + $\mathrm{ixRCC}$
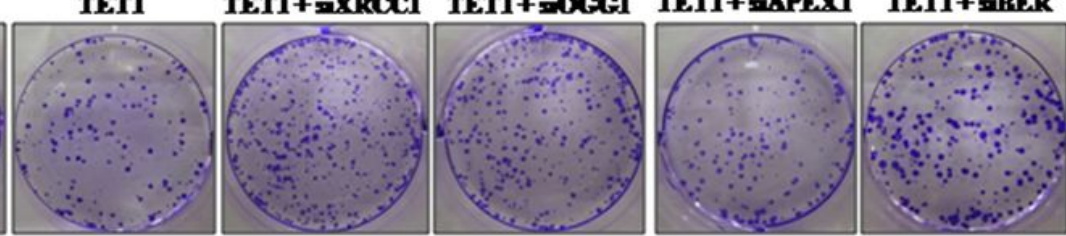

C

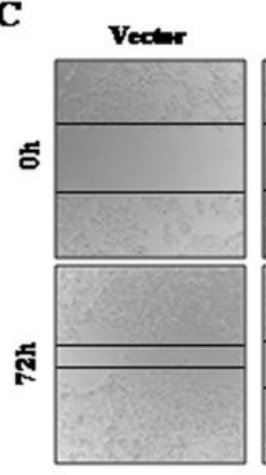

TETI
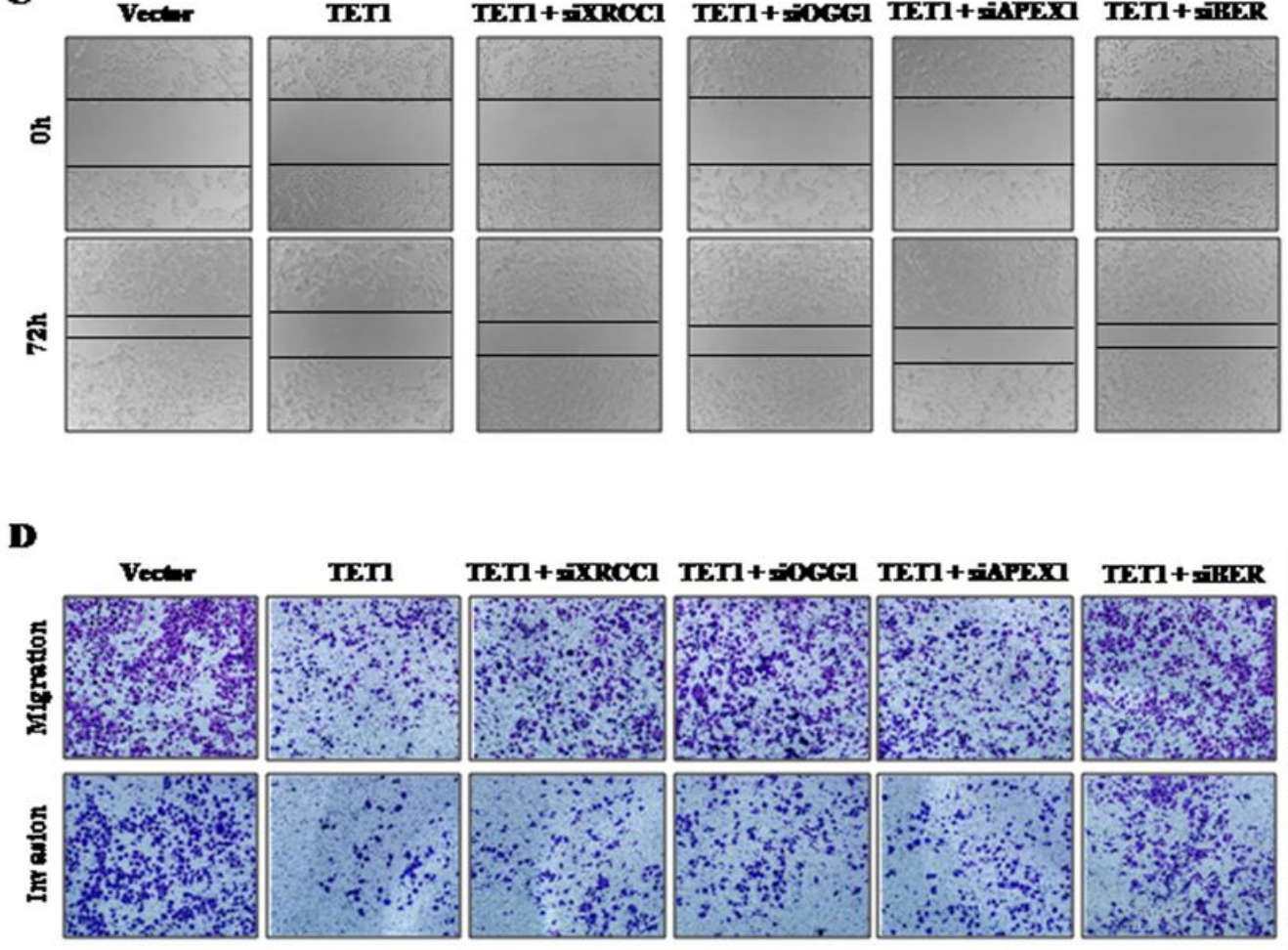
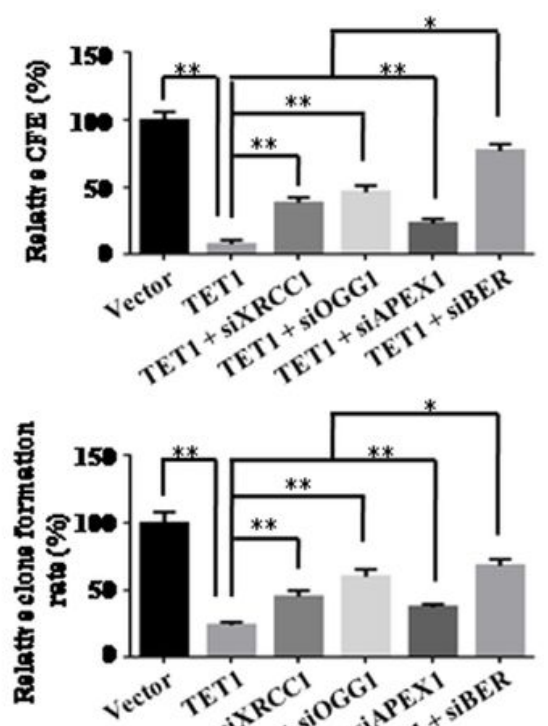

का
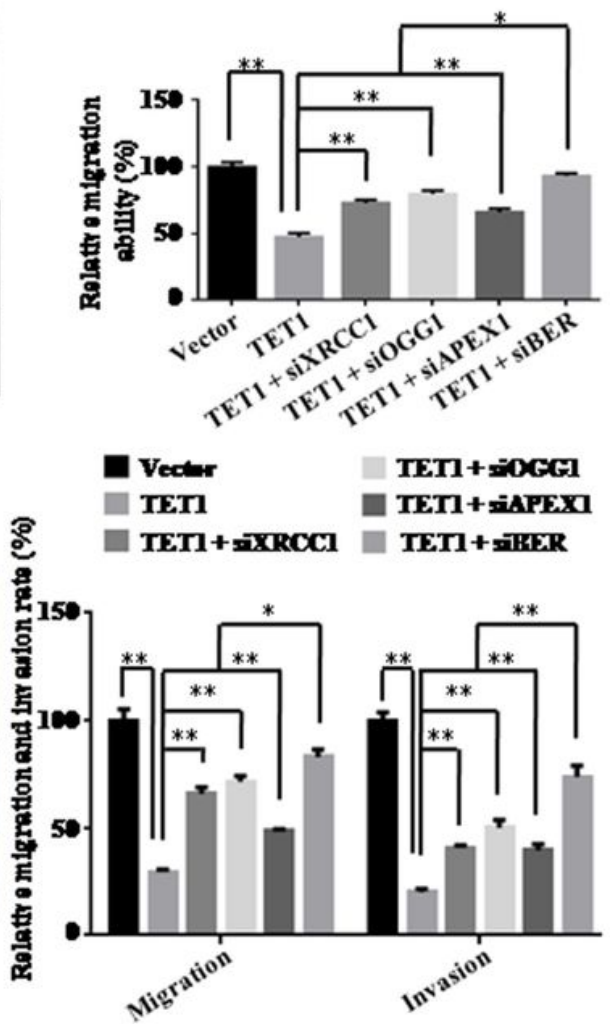

Figure 7 
The effect of BER pathway intervention on the function of TET1 gene in lung cancer. A and B. Soft agar colony formation experiment (A) and Clone formation experiment (B) of lung cancer cells. OGG1, XRCC1, APEX1 was knocked down alone or in combination to treat the cells while over-expressing TET1 gene, the colony formation ability of cell growth was significantly up-regulated. C and D. The scratch healing experiment (C) and Transwell experiment (D) was performed to detected the migration and invasion, after cells was treated with BER pathway invention alone or in combination while overexpression of TET1 gene. It was found that the ability of migration and invasion was significantly increased. $* \star P<0.01$.

\section{Supplementary Files}

This is a list of supplementary files associated with this preprint. Click to download.

- Figures2.tif

- Figures2.tif

- Figures2.tif

- Figures3.tif

- Figures3.tif

- Figures3.tif

- SupplementaryTable.doc

- SupplementaryTable.doc

- SupplementaryTable.doc

- Figures1.tif

- Figures1.tif

- Figures1.tif 